\title{
ANOPHTHALMOS : \\ An unpublished Manuscript by James Briggs \\ giving the first account of the familial \\ occurrence of the condition
}

BY

\section{ARNOLD SORSBY}

LONDON

In his Prodiogorum ac ostentorum chronicon . . . Anno mundi 3772. Basle [1557] a strange medley of fact and fable, Lycosthenes relates of a child lacking eyes and ears but otherwise well formed. The same curiosity is noted by Schenk a Grafenberg in a similar publication (Monstrorum historia, Frankfort, 1609). The earliest creditable account of bilateral anophthalmos comes from Thomas Bartholin (Historiaruin anatomicarum rariorum. Centuria III. Observatio 47. Amsterdam, 1657). Bartholin relates of an anophthalmic child showing, in addition, maldevelopment of the nose and mouth, six fingers on each hand and six toes on the left foot. Subsequent observations abound, but it was only towards the end of the last century that familial cases of the affection were reported. To this statement two exceptions must be made, to both of which Treacher Collins drew attention in his article on Anophthalmos (Ophthal. Hosp. Repts., Vol. XI, p. 429, 1887). One is a short note in the Lancet, Vol. II, p. 109, 1831-32, in which John Walker, "one of the Assistant Surgeons of the Manchester Eye Institution, etc.," reports

\begin{abstract}
" two children (sisters), the elder five years of age, the younger four months. It may be mentioned by the way, that the parents have an intermediate child, a boy, happily free from this lamentable defect. Exactly the same appearances are observable in both. Instead of the natural convexity of the eye-lids, supported by the globe, they have the sunken appearance commonly presented where the contents of the orbit have been evacuated or removed. The aperture between them is very small, not exceeding a quarter of an inch in the transverse direction, but they appear to possess the usual muscular movements.

The orbit appears to be occupied merely with the common cellular substance, which affords little resistance when the finger is applied over the lid. When the children cry, copious lachrymation takes place, proving the existence of a lachrymal gland, but the tears always roll down the cheeks in consequence of the non-existence of the puncta lachrymalia. So that, in a word, these cases may be described as consisting in a total absence of the globe of the eye from each orbit, attended with a like deficiency of the lachrymal passages."
\end{abstract}

The other is a footnote in Weller's Manual of The Diseases of the Human Eye (Vol. II, p. 207, Glasgow, 1821) by its translator, G. C. Monteath :

"I have twice visited the family of W. L., a respectable grocer in the neighbourhood of this city (Glasgow). The first, second, and fourth of his children (eight in number) were born without any vestige of eye-balls. The two eldest of these 
children were otherwise perfectly formed and healthy, but the second died in her sixth year from chincough; the third was born a delicate child, and died when eight months old. Their eye-lids and the lachrymal passages were perfectly natural. These children have been repeatedly attacked with inflanimation of the eye-lids and cavity of the orbit. The edges of the tarsi of the eldest, now a boy of fourteen years of age, have, in consequence of these inflammations, adhered to a considerable extent (Anchyloblepharon imperfectum) so that the opening in to the sockets is now very small."

Familial anophthalmos is an extremely rare condition. Strange it is that whilst Monteath observed a family in Glasgow in 1821 and Walker another in Manchester in 1832 yet a third family was observed in London in 1813-26. The account of this family is fuller than the reports by Monteath and Walker and is contained together with description of an ovarian dermoid in an unpublished MS. by James Briggs, at the library of the Royal College of Surgeons (275 h 2 17). Both for its fulness and because it must be considered the earliest account of the familial occurrence of anophthalmos Briggs's account deserves publication :

\section{Some Particulars of a family in which four of the children} were born with a total deficiency of the eye-ball.

Among the great variety of malconformations of the human body which have been recorded, I have met with no account of a total deficiency of the eye-ball, except in those cases of monstrosity in which the brain itself has been wanting and where the organs which are dependent on it, must of necessity be wholly or in part defective.

An example of this kind however having come within my own observation a few years ago, not in a solitary instance but in several members of the same family, a relation of the principal circumstances of so singular a phenomenon may not in a physiological point of view be wholly without interest.

Clarke and Mary Willding, the parents of the unhappy offspring alluded to, were to all appearance healthy, both of fair complexion and slight form, the size of the eye-ball in each was small, but not in such a degree as to be remarkable, and had not my attention been particularly directed to this point it might have passed without my observation. The age of the father was about 40 , the mother 35 . they have had seven children, four of these were born without any appearance of eye-ball and are now living (an: 1813). Of the three children born in a natural state one only, the eldest, survives. The following is a list of their respective ages, from which it will appear that this peculiar defect was neither connected with the sex nor the order of the succession of their births.

$\begin{array}{llll}\text { 1. Charles } & \text { Aetat. } 20 \\ \text { 2. John } & \text { " } & 18 \text { blind, both eye-balls deficient. } \\ \text { 3. Jane } & \text { " } & 12 \text { blind, both eye-balls deficient. } \\ \text { 4. Mary } & \text { " } & 5 \frac{1}{2} \text { dead. } \\ \text { 5. George } & \text { " } & 1 \frac{1}{2} \text { dead. } \\ \text { 6. Mary } & \text { " } & 5 \text { blind, both eye-balls deficient. } \\ \text { 7. George } & \text { " } & 6 \text { blind, eye-ball of the right side deficient, eye-ball } \\ \text { of the left side malformed. }\end{array}$

In all the four instances of malformation with the exception of the last, the appearances connected with this defect were precisely similar so that the description of one of these will serve for the rest.

On each side there was a total deficiency of the eye-ball. The eye-lids which were constantly kept closed were much smaller than natural and beset with strong.

[* Though thus written, apparently means 6 weeks, see below.] 
dark eye-lashes. The opening between them was only large enough to admit a crow's quill. On examination the tarsal cartilages were distinctly perceptible, and the presence of the lachrymal gland was sufficiently demonstrated by the secretion of tears. so that the external apparatus of the organ might be said to be complete. In the place of the eye-ball, there was a small funnel-shaped opening formed by a continuation of the membrane lining the eye-lid, and terminating towards the posterior part of the orbit by a small aperture into which the point of a probe could be readily introduced. On passing a probe into this aperture at the lower part of the orbit in order to determine the extent of it, the irritation which it excited occasioned a copious flow of tears.

In the youngest child (George), 6 weeks old, the eye of the right side was entirely wanting, presenting the peculiar appearances already described in the other children. On the left side the organization of an eye-ball was perceptible, but the part was so diminutive that the cornea represented merely a black speck upon it scarcely exceeding the size of a pin's head. From the exceeding minutiveness of the parts, the almost constant closure of the palpabrae, and the perpetua rolling motion of the eye, there could be no reason to conclude that the child had any perception of light, much less power of vision. The mother, however, affirmed that the child manifested some uneasiness whenever the strong light of a candle was brought near to it.

Six or seven months after this memorandum was made John, the eldest of the blind children, died. I was informed by his mother that this took place after a few days' illness without any particular marks of his labouring under a fatal disease except great palpitation of the heart. This circumstance, together with a remarkable blueness of the lips and finger-nails which he had had from birth, leaves little doubt that there existed, at the same time in this instance, that remarkable malformation of the heart in which from a deficiency of the septum the venous and arterial blood became mixed. In the other children no such appearance is observable, and it may therefore be presumed that the defective formation is in them confined to the organ of vision alone.

My observation being directed to the changes which took place in the infant before mentioned, I found at the end of 6 months no perceptible difference in the eye-ball, except that it had increased in growth with the rest of the body. At three years of age the organ was so far developed that its form could be more accurately defined.

The cornea was at this period something less than $\frac{1}{4}$ of an inch in diameter. flattened on its surface, and its texture extremely dense; yet it was evident that he possessed the power of distinguishing light and the involuntary motion of the eye continued unabated.

I had lately an opportunity of seeing this boy, now in his 13 th year, and found the parts to have undergone no change except in bulk, and this was chiefly confined to the schlerotic portion of the eye, the cornea remaining nearly in the state already described. He possessed, however, more command over its motions, and had a strong perception of light.

I am disposed to believe that this example of original defective formation of the organ of sight, constitutes a species of congenital blindness not extremely rare, having met with one or more instances of a similar kind in adults in which this wasted appearance of the eye could not be traced as consequent upon any injury or previous disorder.*

The increased powers of certain organs of sense or of the mental faculties depending on them, where there has been a privation of others, has been often remarked, and is strikingly exemplified in the elder sister with regard to the memory of sounds. Having been taught music she is able by three or four repetitions only of the subject, the notes being simply repeated to her, to retain and execute passages even of considerable length.

The mother of the children being dead, the father has married again and has, by his second wife, two children, both healthy and well formed.

\section{J. BRIGGS.}

* The general appearance of the eye in these cases resembles very strongly the shrunk-state of this organ, where the humours have been discharged in consequence either of internal suppuration and rupture of the tunics, or of unsuccessful operations performed upon it. 
The aetiology of anophthalmos is still a disputed problem. The paper by Briggs is sufficiently detailed to constitute a contribution to the literature on the subject even to-day-well over a century after it was written. It supports those who believe that the explanation must be sought along the lines of recessive hereditary maldevelopments rather than in ante-natal inflammatory processes.

James Briggs is known to ophthalmology as the translator of Scarpa's Practical observations on the principal diseases of the eye of which two editions appeared, one in 1806, the other in 1818. $\mathrm{He}$ was one of the growing number of general surgeons at the beginning of the last century who were turning to the study of ophthalmology. In the preface to the second edition of his translation he pleads eloquently against the neglect of the speciality by the general surgeons. As surgeon to the Lock Hospital his main interest would appear to have been surgical. In addition to two other translations of publications on general surgery by Scarpa, he himself contributed a short monograph on Treatment of Strictures of the Urethra by Mechanical Dilatation (London, 1845). What little is known of his life is contained in a short note in Plarr's Lives of the Fellows of the Royal College of Surgeons of England, based on information in the obituary notice in the Lancet, Vol. I, p. 406, 1848. His date of birth is not known. He became M.R.C.S. in 1804 and was one of the original 300 fellows of the College (1843), to the Council of which he was co-opted in 1828. He died on March 29, 1848.

I am obliged to Mr. R. R. James for the following additional information: a James Briggs took a three months' course of study at St. George's Hospital under Mr. Home (later Sir Everard Home) on July 7, 1802, and a further three months' course in September of the same year.

I am indebted to Mr. W. R. Le Fanu, Librarian of the Royal College of Surgeons' Library, for permission to publish the Briggs M.S., for the footnote on the age of the seventh child, and for his interest in this paper. To Mr. S. Wood, of the Library staff, I am indebted for his never-failing courtesy and for the careful transcription of the MS. 